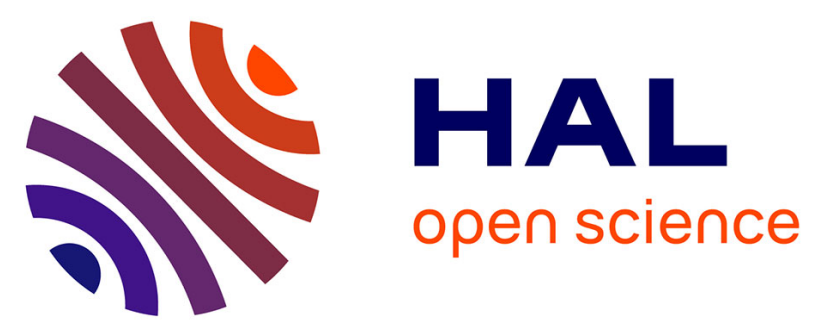

\title{
Maternal-fetal transmission and adverse perinatal outcomes in pregnant women infected with Zika virus: prospective cohort study in French Guiana
}

Léo Pomar, Manon Vouga, Véronique Lambert, Céline Pomar, Najeh Hcini,

Anne Jolivet, Guillaume Benoist, Dominique Rousset, Séverine Matheus, Gustavo Malinger, et al.

\section{To cite this version:}

Léo Pomar, Manon Vouga, Véronique Lambert, Céline Pomar, Najeh Hcini, et al.. Maternal-fetal transmission and adverse perinatal outcomes in pregnant women infected with Zika virus: prospective cohort study in French Guiana. BMJ, 2018, 363, pp.k4431. 10.1136/bmj.k4431 . hal-01922382

\section{HAL Id: hal-01922382 \\ https://hal.sorbonne-universite.fr/hal-01922382}

Submitted on 14 Nov 2018

HAL is a multi-disciplinary open access archive for the deposit and dissemination of scientific research documents, whether they are published or not. The documents may come from teaching and research institutions in France or abroad, or from public or private research centers.
L'archive ouverte pluridisciplinaire HAL, est destinée au dépôt et à la diffusion de documents scientifiques de niveau recherche, publiés ou non, émanant des établissements d'enseignement et de recherche français ou étrangers, des laboratoires publics ou privés.

\section{(ㅇ)(1) $\$$}

Distributed under a Creative Commons Attribution - NonCommerciall 4.0 International 

pregnant women infected with Zika virus: prospective cohort study in French Guiana

\author{
Léo Pomar, ${ }^{1,2}$ Manon Vouga, ${ }^{1}$ Véronique Lambert, ${ }^{2}$ Céline Pomar, ${ }^{1,2}$ Najeh Hcini, ${ }^{2}$ \\ Anne Jolivet, ${ }^{3,4}$ Guillaume Benoist, ${ }^{5}$ Dominique Rousset, ${ }^{6}$ Séverine Matheus, ${ }^{6}$ \\ Gustavo Malinger, ${ }^{7,8}$ Alice Panchaud, ${ }^{9,10,11}$ Gabriel Carles, ${ }^{2}$ David Baud ${ }^{1}$
}

For numbered affiliations see end of article.

Correspondence to: D Baud david.baud@chuv.ch

(or@GroupBaud on Twitter ORCID 0000-0001-9914-6496) Additional material is published online only. To view please visit the journal online.

Cite this as: $B M J$ 2018;363:k4431 http://dx.doi.org/10.1136/bmj.k4431

Accepted: 3 October 2018

\section{ABSTRACT}

OBJECTIVES

To estimate the rates of maternal-fetal transmission of Zika virus, adverse fetal/neonatal outcomes, and subsequent rates of asymptomatic/symptomatic congenital Zika virus infections up to the first week of life.

\section{DESIGN}

Cohort study with prospective data collection and subsequent review of fetal/neonatal outcomes.

\section{SETTINGS}

Referral centre for prenatal diagnosis of the French Guiana Western Hospital.

\section{PARTICIPANTS}

Pregnant women at any stage of pregnancy with a laboratory confirmed symptomatic or asymptomatic Zika virus infection during the epidemic period in western French Guiana. The cohort enrolled 300 participants and prospectively followed their 305 fetuses/newborns.

\section{MAIN OUTCOME MEASURES}

Rate of maternal-fetal transmission of Zika virus (amniotic fluid, fetal and neonatal blood, urine, cerebrospinal fluid, and placentas); clinical, biological, and radiological outcomes (blindly reviewed); and adverse outcomes defined as moderate signs potentially related to congenital Zika syndrome (CZS), severe complications compatible with CZS, or fetal loss. Associations between a

\title{
WHAT IS ALREADY KNOWN ON THIS TOPIC
}

Many reports have described the spectrum of congenital Zika virus syndrome in severely affected fetuses/newborns during the recent epidemics

Early reports suggested a risk of fetal anomalies up to $40 \%$, whereas more recent reports agree on a rate of Zika virus related birth defects of $4-8 \%$ in cases of confirmed maternal infection

The absolute risk of maternal-fetal infection remains difficult to establish owing to the lack of fetal/neonatal testing, especially in apparently healthy newborns, and is therefore rarely reported

\section{WHAT THIS STUDY ADDS}

This paper presents the results of fetal/neonatal testing and early clinical outcomes of 291 fetuses/newborns from Zika virus infected pregnant women during the recent epidemic in French Guiana

Maternal-fetal transmission seems to occur in approximately a quarter of exposed fetuses and is associated with early adverse fetal/neonatal outcomes in a third of infected fetuses

laboratory confirmed congenital Zika virus infection and adverse fetal/neonatal outcomes were evaluated.

RESULTS

Maternal-fetal transmission was documented in $26 \%(76 / 291)$ of fetuses/newborns with complete data. Among the Zika virus positive fetuses/ newborns, 45\% (34/76) presented with no signs/ complications at birth, $20 \%(15 / 76)$ with moderate signs potentially related to CZS, $21 \%(16 / 76)$ with severe complications compatible with CZS, and $14 \%$ $(11 / 76)$ with fetal loss. Compared with the Zika virus positive fetuses/neonates, those that were identified as negative for Zika virus (215/291) were less likely to present with severe complications $(5 \% ; 10 / 215)$ or fetal loss ( $0.5 \%$; $1 / 215$; relative risk $6.9,95 \%$ confidence interval 3.6 to 13.3). Association between a positive Zika virus test and any adverse fetal/ neonatal outcome was also significant (relative risk $4.4,2.9$ to 6.6 ). The population attributable fraction estimates that a confirmed congenital Zika virus infection contributes to $47 \%$ of adverse outcomes and $61 \%$ of severe adverse outcomes observed.

\section{CONCLUSION}

In cases of a known maternal Zika virus infection, approximately a quarter of fetuses will become congenitally infected, of which a third will have severe complications at birth or fetal loss. The burden of CZS might be lower than initially described in South America and may not differ from other congenital infections.

\section{Introduction}

The recent epidemics in French Polynesia and the Americas have confirmed vertical trans-placental transmission of Zika virus and its association with congenital anomalies, particularly severe central nervous system lesions. ${ }^{1-3}$ Nevertheless, the exact burden of disease remains unclear, especially in endemic countries. Similarly to congenital cytomegalovirus and toxoplasmosis infections, vertical transmission is not systematic and does not always lead to fetuses/infants with apparent signs of infection. ${ }^{4}$ The risk of congenital Zika virus syndrome (CZS) was estimated, at first, to be higher than $40 \%$ in a cohort of women who developed symptomatic Zika virus infection during pregnancy in Brazil, ${ }^{5}$ whereas more recent data from the US Zika pregnancy registry suggest an overall risk of $5 \%$ and up to $8 \%$ in cases of maternal infection in the first trimester. ${ }^{6}$ The lack of fetal/neonatal testing in previous studies has impaired 
accurate estimations of maternal-fetal transmission and risk of symptomatic congenital infection.

We conducted a cohort study among pregnant women in western French Guiana during the recent Zika virus epidemic and evaluated the results of comprehensive fetal/neonatal testing for Zika virus. Our primary objective was to estimate the absolute risk of maternalfetal infection. The secondary objectives were to estimate the percentage of fetuses/newborns with overt signs of infection or related complications within the first week of life, by reviewing fetal/neonatal outcomes blinded to Zika virus status; to estimate the relative risk of adverse perinatal outcomes in infected fetuses; and to estimate the population attributable fraction of a confirmed congenital Zika virus infection for any adverse outcome and for severe adverse outcomes.

\section{Methods}

\section{Study population}

The study was conducted at the French Guiana Western Hospital Center (Centre Hospitalier de l'Ouest Guyanais; CHOG) during the Zika virus epidemic. French Guiana is a French department located in South America, and in 2015 it had an estimated total population of 252338 and 6800 births. $^{7}$ The Zika virus epidemic in French Guiana lasted nine months from January to September 2016, with a total of 9790 suspected cases, affecting mostly the coast and western part of French Guiana. ${ }^{89}$ All pregnancies in the territory were offered monitoring by real-time polymerase chain reaction (RT-PCR) and/or detection of Zika virus antibodies as the consequence of an awareness policy adopted in the French Departments of America. ${ }^{10}$ During this period, a total of 1105 pregnant women presented with a positive Zika virus test and were monitored in three referral centres-the CHOG, the Centre Hospitalier de Cayenne, and the Centre Medico-Chirurgical de Kourou. ${ }^{811}$

The CHOG is located in the western part of French Guiana, in Saint Laurent du Maroni. With a total of 284 beds, it is the second largest hospital in French Guiana and includes a maternity unit providing neonatal intensive care. The catchment population of the CHOG is quite similar of that of all French Guiana, but some particularities come from the fact that a part of the western population live along the Maroni river and are more exposed to poverty, difficult living conditions, and subsequent medical comorbidities (higher rates of pregnancy among adolescents and higher risks of prematurity, vascular diseases, lead poisoning, and anaemia). We identified patients for inclusion in the study either through routine serological testing of all pregnant women admitted to the prenatal unit of the CHOG (irrespective of the trimester of pregnancy or presence of symptoms) or through serological and molecular testing of pregnant women with Zika virus symptoms admitted in our department (fig 1). We included patients with a confirmed Zika virus infection during pregnancy from 1 January to 15 July $2016 . .^{811}$ The enrolment period thus occurred in the early stages of the Zika virus epidemic in French Guiana. We excluded patients not monitored in our prenatal diagnosis unit after the diagnosis of Zika virus infection owing to the lack of prenatal follow-up, patients with fetal losses before 14 weeks' gestation, and patients for whom the diagnosis of Zika virus infection was based on serology performed at delivery. We excluded the last group because of the lack of prospective follow-up during pregnancy and comprehensive fetal/neonatal assessment during the first week of life, as Zika virus status was available only after discharge from hospital (at the peak of the epidemic, results were delayed by as much as two weeks owing to limited technical and human resources).

Patients included in the study provided written informed consent after discussing the objectives of the study. We collected data on demographic characteristics, medical parameters, and possible risk factors for congenital diseases. ${ }^{11}$ Pregnancies were monitoredas clinically indicated, except for theaddition of prenatal ultrasound scans performed monthly during the Zika virus epidemic as recommended by the French authorities. In France, prenatal screening for aneuploidy, HIV, toxoplasmosis, rubella, and syphilis are offered to all pregnant patients during the first trimester. Screening for cytomegalovirus, herpes simplex viruses, and parvovirus B19 (TORCH screening) is proposed in cases of suspected maternal/ fetal infection. Gestational age was based on the crown-rump length on an ultrasound scan performed between 11 and $13^{+6}$ weeks' gestation. Prenatal care as outlined above was supported by the French maternity insurance available to all pregnant women, regardless of their socioeconomic conditions.

\section{Laboratory confirmation of Zika virus infection}

We defined pregnant patients as positive for Zika virus either by a positive RT-PCR result performed with the Realstar Zika Kit (Altona Diagnostics GmbH, Hamburg, Germany) in blood and/or urine samples or by the presence of Zika virus specific IgM after detection of antiZika virus antibodies in the blood. Serological testing (including Dengue and Chikungunya) was performed at the French Guiana National Reference Centre for arboviruses. For Zika virus, we used an in-house MACELISA assay, with a sensitivity, when correlated with PCR results, varying between $87 \%$ for serum samples collected between five and 20 days from symptom onset to $98 \%$ for those collected after seven days. ${ }^{10}$ Specificity varies depending on the presence of co-infections with other arboviruses, reaching $80 \%$ in negative patients, but dropping in the case of co-infections. ${ }^{10}$ In such cases $(n=18)$, we obtained confirmation with a microneutralising assay. Serological cross reactions with other Flaviviridae were expected to be minimal, as circulation of Dengue virus has been low in French Guiana since 2014 and no significant circulation of other Flaviviridae has been seen. ${ }^{12}$

We defined a confirmed congenital Zika virus infection either by Zika virus RNA amplification by RT-PCR from at least one fetal/neonatal sample (placenta, amniotic fluid, cerebrospinal fluid, urine, or blood) or identification of Zika virus specific IgM in 


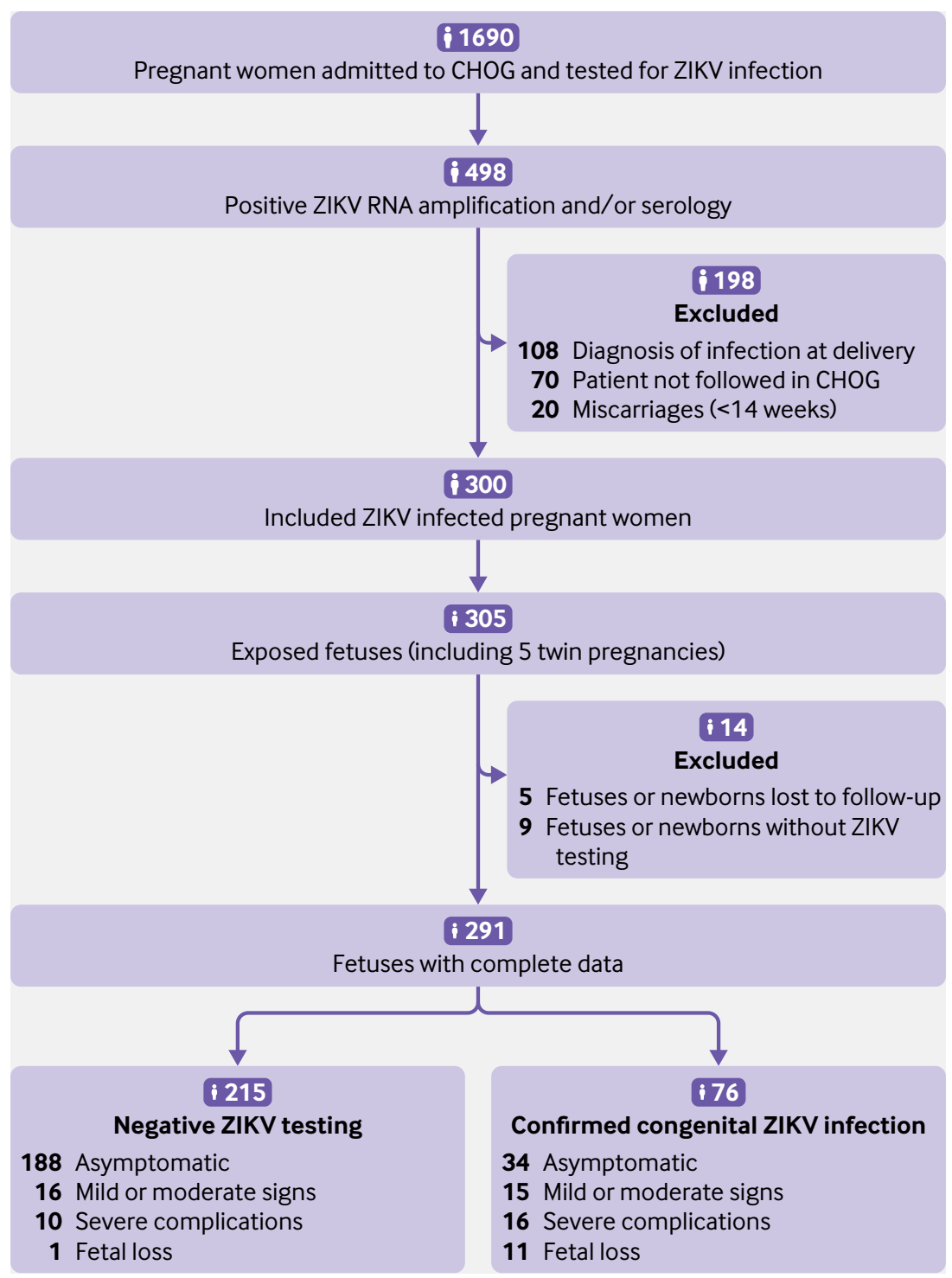

Fig 1 | Prospective maternal cohort and neonatal/fetal outcomes. Pregnant women admitted to French Guiana Western Hospital Center (Centre Hospitalier de l'Ouest Guyanais; $\mathrm{CHOG}$ ) were routinely tested for Zika virus specific IgM and/or Zika virus RNA. Patients with a positive test were offered participation in the study. ZIKV=Zika virus

the umbilical cord/neonatal blood or in cerebrospinal fluid. Zika virus status was confirmed at day three of life by IgM serology to exclude maternal contamination of umbilical cord blood in all liveborn neonates (except in four neonates whose parents declined). In cases of fetal loss, blood status was defined only by umbilical cord samples.

\section{Fetal/neonatal outcomes}

We followed fetuses/newborns from mothers positive for Zika virus up to their first week of life and collected data as well as results of neonatal/fetal testing.

\section{Laboratory tests}

When a fetal malformation was suspected, invasive testing was offered to complete TORCH PCRs, karyotype, and comparative genomic hybridisation array if necessary, after discussion with an expert fetal multidisciplinary centre (Caen University Hospital, France), according to French legislation. All fetuses underwent haematological and biochemical screening at birth, performed on cord and/or neonatal blood before the third day of life.

\section{Fetal/neonatal imaging}

Pregnant women had monthly ultrasound examinations from the time of diagnosis of Zika virus infection until delivery, with standardised biometric measurements and anatomical evaluation, paying special attention to the brain anatomy, as recommend by national and international medical societies. ${ }^{13} 14$ All fetal ultrasound examinations were performed by two experienced sonographers (VL, LP) using E8 and E10 Voluson ultrasounds with abdominal (RM6C) and transvaginal (RIC5-9-D) transducers (General Electric Medical System, Milwaukee, USA).

A transfontanellar ultrasound scan was offered for all neonates during the first week of life, using Phillips EPIQ 7g ultrasound with a neonatal cephalic (C8-5) transducer (Phillips Medical Systems, Cleveland, USA). Computed tomography scanning was not offered routinely owing to the limited capacity of the local radiology unit and was done only if calcifications or skull abnormality were suspected (on prenatal or postnatal ultrasound scans or clinical assessment for skull abnormalities). The radiology unit did not offer magnetic resonance imaging, and the nearest scanner was located $300 \mathrm{~km}$ away. Because of these limitations, computed tomography and magnetic resonance imaging examinations were performed after the first week of life and data are not reported in this study.

\section{Neonatal clinical assessments}

All neonates underwent clinical examination at birth by a midwife and at day three of life by a senior neonatologist. A complete physical examination was performed with special attention to anthropometric measurements, neurological status, and signs of infection, as recommended by international medical societies. ${ }^{15}$ Anthropometric measurements were assessed according to the Intergrowth charts available at https://intergrowth21.tghn.org/standards-tools/.

\section{Fetal/neonatal outcome definitions}

On the basis of previously published criteria to define congenital Zika virus and cytomegalovirus infections, ${ }^{16-19}$ we used minor and major signs to define four categories (appendix 1). (1) Asymptomatic was defined as no major signs and less than two minor signs. (2) Mild/moderate signs potentially associated with CZS were defined as no major signs and at least two minor signs. (3) Severe complications compatible with CZS were defined as one major sign or three minor signs including at least one cerebral anomaly identified on prenatal or postnatal ultrasound. (4) Fetal loss was defined as the spontaneous demise of the fetus after 14 weeks' gestation. Fetal loss includes late miscarriages (14-24 weeks) $^{20}$ and stillbirths (fetal demise $>24$ weeks) but not intrapartum nor early postpartum 


\begin{tabular}{|c|c|c|}
\hline Characteristics & Laboratory confirmed cZIKV infection $(n=76)$ & Negative fetal/neonatal ZIKV testing $(n=215)$ \\
\hline Median (interquartile range) maternal age, years & $26.7(23.0-32.4)$ & $27.5(22.3-33.1)$ \\
\hline Maternal age $>35$ years & $12(16)$ & $40(19)$ \\
\hline Any maternal comorbidities* & $21(28)$ & $42(20)$ \\
\hline Diabetes (previous or gestational) & $2(3)$ & $10(5)$ \\
\hline Vascular pathologies & $6(8)$ & $14(7)$ \\
\hline Thrombophilia & $2(3)$ & $2(1)$ \\
\hline Anaemia & $4(5)$ & $4(2)$ \\
\hline Co-infections & $3(4)$ & $7(3)$ \\
\hline Lead poisoning & $2(3)$ & $5(2)$ \\
\hline Alcohol consumption & $1(1)$ & $1(0.5)$ \\
\hline Others & $3+(4)$ & $3 \neq(1)$ \\
\hline \multicolumn{3}{|l|}{ Risk of fetal aneuploidy: } \\
\hline High risk $(\geq 1 / 250)$ & $2(3)$ & $3(1)$ \\
\hline Low risk $(<1 / 250)$ & $47(62)$ & $117(54)$ \\
\hline Late follow-up§ & $27(36)$ & $95(44)$ \\
\hline \multicolumn{3}{|l|}{ Trimester of suspected maternal infection: } \\
\hline First & $16(21)$ & $52(24)$ \\
\hline Second & $44(58)$ & $111(52)$ \\
\hline Third & $16(21)$ & $52(24)$ \\
\hline \multicolumn{3}{|c|}{$\begin{array}{l}\text { cZIKV=congenital Zika virus. } \\
\text { *Including patients with multiple comorbidities. } \\
\text { †Anti-Lea alloimmunisation; denutrition; vitamin K deficiency. } \\
\text { fIncreased human chorionic gonadotropin concentrations; history of mucopolysaccharidosis. } \\
\text { §Clinical follow-up started after first trimester. }\end{array}$} \\
\hline
\end{tabular}

deaths. ${ }^{21}$ We defined "any adverse outcomes" as mild/moderate signs potentially associated with CZS or severe complications compatible with CZS or fetal loss $(2+3+4)$ and "severe adverse outcomes" as severe complications compatible with CZS or fetal loss $(3+4)$.

Three independent reviewers (LP, MV, DB) blinded to Zika virus status reviewed all fetal/neonatal outcomes and classified them into the four categories described above on the basis of prenatal/transfontanellar ultrasound findings, symptoms at birth, and haematological and biochemical blood analyses (appendix 1). Discrepant cases were discussed between reviewers to determine the most appropriate classification.

\section{Statistical analyses}

We compared the demographic and clinical variables of Zika virus positive and negative fetuses/newborns. We used the binomial Wilson score to calculate confidence intervals of single proportions and the Pearson exact method to calculate confidence intervals of risk ratios and medians. We present denominators where data for the secondary outcome are missing. We defined the population attributable fraction as $(\mathrm{Re}-\mathrm{Run}) / \mathrm{Re}=(\mathrm{RR}-1) / \mathrm{RR}$, calculated using Stata. To test the robustness of our findings, we did a sensitivity analysis. As the placenta might be contaminated by maternal blood, we redefined the criteria for a laboratory confirmed congenital Zika virus infection to exclude placentas and removed them from the analysis. We used Stata 14 for data analyses.

\section{Patient and public involvement}

This research was done without patient involvement. Patients were not invited to comment on the study design and were not consulted to develop patient relevant outcomes or interpret the results. Patients were not invited to contribute to the writing or editing of this document for readability or accuracy. We have invited the public to help us to develop our dissemination strategy.

\section{Results}

From 1 January to 15 July 2016, 300 pregnant women with a positive Zika virus test, of whom 52 (17.3\%) presented with compatible symptoms, were monitored in the prenatal diagnosis unit of the CHOG and included in the study, representing a total of 305 exposed fetuses (including five twin pregnancies). Zika virus testing was available for 291 fetuses/newborns and clinical outcomes for 300 fetuses/newborns (fig 1).

\section{Laboratory confirmation of maternal-fetal transmission}

Maternal-fetal transmission was documented in $76 / 291$ (26\%, 95\% confidence interval $21 \%$ to $32 \%$ ) of fetuses/newborns with complete data. Positive Zika virus results were obtained from 48/280 (17\%) umbilical/neonatal cord blood samples (confirmed at day three of life for liveborn neonates), 51/232 (22\%) placentas, $7 / 247$ (3\%) urine samples, 5/12 (42\%) amniotic fluid samples, and 4/7 (57\%) cerebrospinal fluid samples. When we excluded placental samples from the analysis, maternal-fetal transmission was documented in 52/282 (18\%, 14\% to $23 \%)$ fetuses/ newborns with other samples tested.

Among fetuses/newborns with negative testing, 4/215 (2\%) had four different samples tested, 167/215 (78\%) had three different samples tested, 36/215 (17\%) had two different samples tested, and 8/215 (4\%) had only one sample tested. Among fetuses/ newborns with a laboratory confirmed Zika virus 
infection, 1/76 (1\%) had five different samples tested, $3 / 76$ (4\%) had four different samples tested, 38/76 (50\%) had three different samples tested, 15/76 (20\%) had two different samples tested, and 19/76 (25\%) had only one sample tested (appendix 2).

As shown in table 1, no significant differences in baseline maternal characteristics existed between the two groups. We also observed similar baseline maternal characteristics between patients included in and excluded from the cohort, as well as in all patients delivered at CHOG during 2016 (appendix 3). Cases of maternal co-infection among fetuses/neonates with a laboratory confirmed Zika virus infection included two active hepatitis $B$ infections. In fetuses with a negative Zika virus test, two HIV, two primary toxoplasmosis, one human T-lymphotropic virus, one Coxsackie virus, one primary varicella zoster virus, and one leptospirosis were recorded. The timing of diagnosis of maternal infection was similar between fetuses/newborns with a confirmed Zika virus infection and those with no laboratory evidence of a Zika virus infection.

\section{Fetal/neonatal outcomes}

Among exposed fetuses ( $n=291), 210(72 \%, 67 \%$ to $77 \%$ ) presented with no signs/complications at birth, $31(11 \%, 8 \%$ to $15 \%)$ presented with mild/moderate signs potentially related to CZS, 26 (9\%, 6\% to $13 \%)$ presented with severe complications compatible with CZS (including three medical termination of pregnancy), and 12 (4\%, 2\% to $7 \%$ ) fetal losses were recorded (fig 2).

Among the 76 fetuses/neonates with a documented congenital Zika virus infection, 34 (45\%, 34\% to 56\%) presented with no signs/complications, 15 (20\%, 12\% to $30 \%)$ had mild/moderate signs, $16(21 \%, 13 \%$ to $33 \%)$ had severe complications, and $11(14 \%, 8 \%$ to $24 \%$ ) resulted in fetal loss (table 2 ). In contrast, among the 215 fetuses/neonates that tested negative for Zika virus, $188(87 \%, 82 \%$ to $91 \%)$ presented with no signs/ complications, 16 (7\%, 5\% to $12 \%$ ) had mild/moderate signs, $10(5 \%, 3 \%$ to $8 \%)$ had severe complications, and $1(0.5 \%, 0.1 \%$ to $3 \%)$ resulted in fetal loss (table 2$)$. A full description of each fetus/newborn with an adverse outcome is available in appendix 4.

\section{Association between Zika virus exposure and fetal/ neonatal outcomes}

Fetuses/newborns with a laboratory confirmed congenital Zika virus infection had a higher risk of "any adverse outcome" (that is, mild/moderate signs or severe complications or fetal loss) (42/76; 55\% ( $44 \%$ to $66 \%$ ) versus $27 / 215 ; 13 \%$ (9\% to $18 \%$ )) than did those who were considered Zika virus negative by laboratory testing (relative risk 4.4, 95\% confidence interval 2.9 to 6.6). Similarly, the risk of "severe adverse outcomes" (defined as severe complications or fetal loss) was higher in cases of confirmed congenital Zika virus infection (relative risk 6.9, 3.6 to 13.3). The population attributable fraction of a confirmed congenital Zika virus infection was $47 \%$ for any adverse outcome and $61 \%$ for severe adverse outcomes.
When we did our analysis using a more restrictive definition for a confirmed congenital Zika virus infection (that is, sensitivity analysis by excluding placental Zika virus samples owing to potential maternal contamination), the results were similar to those of the main analysis for "any adverse outcomes" (relative risk 4.2, 2.7 to 6.0) and "severe adverse outcome" (5.4, 2.8 to 10.2$)$.

On examination of individual symptoms (table 3), fetuses/newborns with a laboratory confirmed congenital Zika virus infection presented with more frequent jaundice $(19 / 76(25 \%) \quad v \quad 20 / 215$ (9\%)), hypotonia $(10 / 76(13 \%) v 11 / 215(5 \%))$, hypertonia $(5 / 76(7 \%) v 3 / 215(1 \%))$, and swallowing dysfunction $(4 / 76(5 \%) \vee 1 / 215(0.5 \%))$ than did those that tested negative for Zika virus. In newborns with measurements available, head circumference below 2 standard deviations (that is, microcephaly) was observed in $10 \%$ (27/273) of newborns and four newborns presented with a head circumference below 3 standard deviations. The rate of microcephaly was similar between fetuses/ neonates with a laboratory confirmed congenital Zika virus infection and those who tested negative (8/61 $(13 \%) v 19 / 212$ (9\%) for head circumference <2 SD). Biological parameters measured in newborns with a laboratory confirmed congenital Zika virus infection (table 3) identified an increased incidence of anaemia $(17 / 57$ (30\%) v 8/192 (4\%) for haemoglobin <140 g/L) and elevated liver enzymes $(32 / 52(62 \%) v 40 / 155$ $(26 \%)$ for aspartate aminotransferase $>50 \mathrm{U} / \mathrm{L})$. Other biological parameters, such as thrombocytopenia often associated with other congenital infections, did not differ between the groups.

\section{Discussion}

In this paper, we have presented the results of fetal/ neonatal testing and early neonatal outcomes for 291 fetuses/newborns of mothers infected with Zika virus. All fetal/neonatal outcomes were reviewed independently and blindly for Zika virus status. Maternal-fetal transmission was documented in $26 \%$ of fetuses/newborns and was significantly associated with "severe adverse outcomes."

\section{Comparison with other studies}

In our cohort, only 13\% (approximately one in eight) of all fetuses/newborns born to mothers positive for Zika virus presented with "severe adverse outcomes." This is comparable to rates for other congenital infections, such as congenital cytomegalovirus. Maternal-fetal transmission rates of congenital cytomegalovirus are estimated to be $30-35 \%$ in cases of maternal primary infection. Among fetuses infected with cytomegalovirus, only 10-15\% are estimated to present without signs/complications at birth. ${ }^{22}$ This rate can be up to $30 \%$ when considering all observed anomalies and related terminations of pregnancy. ${ }^{23}$ Our large cohort study with complete and comprehensive analysis of early neonatal outcomes including neonatal test results facilitates a well informed estimate of the burden of disease in countries with active Zika 


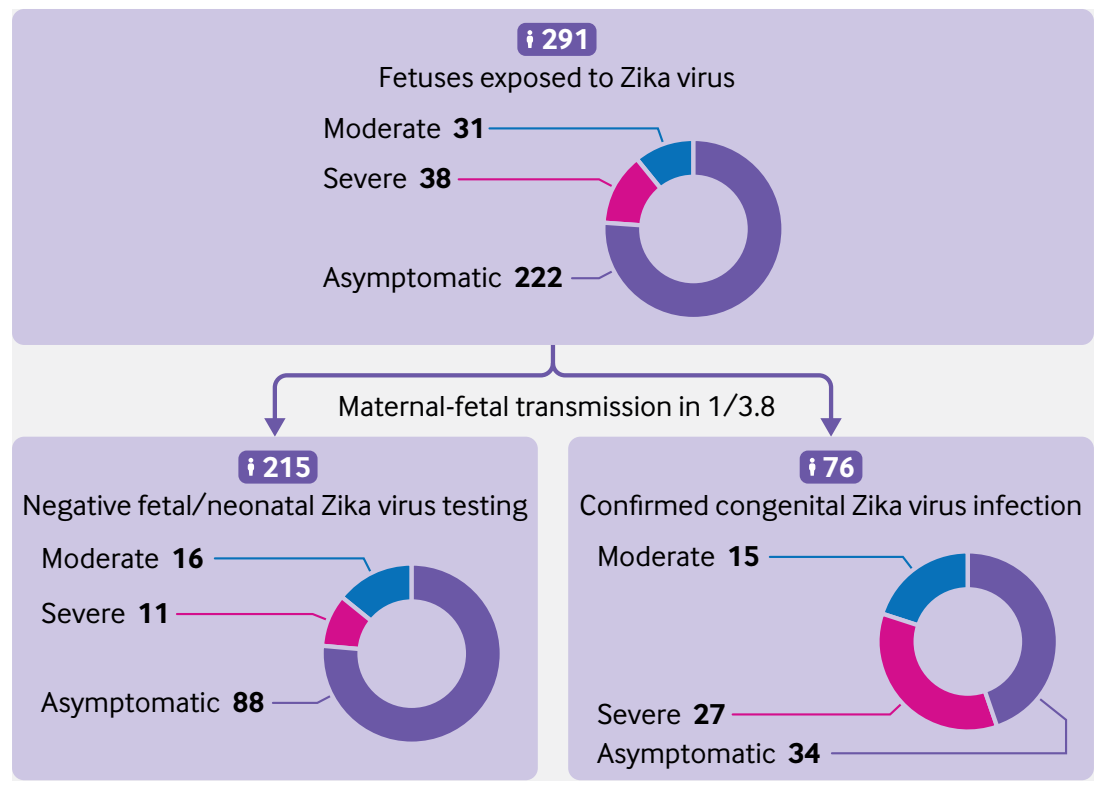

Fig 2 | Maternal-fetal transmission rate and primary fetal/neonatal outcomes. Outcomes and results of fetal/neonatal testing were available for 291 fetuses/newborns. The rate of maternal-fetal transmission was evaluated on the basis of fetal/neonatal testing. A confirmed congenital Zika virus infection was considered when either Zika virus RNA was amplified by real-time polymerase chain reaction from at least one fetal/ neonatal sample (placenta, amniotic fluid, cerebrospinal fluid, urine, or blood) or when Zika virus specific IgM was identified in the umbilical cord/neonatal blood or in cerebrospinal fluid. Each case was reviewed by three independent reviewers, blinded to Zika virus status, and classified into four categories based on prenatal ultrasound findings, symptoms at birth, biological parameters, and postnatal transfontanellar ultrasound (see appendix 1). Discordant classifications were discussed between the three reviewers included in our cohort may have enabled the detection of more uncommon severe anomalies and provided a better estimation of maternal-fetal transmission. The rates of severe anomalies (9\%) and pregnancy losses $(4 \%)$ in our whole cohort of exposed pregnancies are similar to those reported in non-endemic countries; the US Zika pregnancy and infant registry describes rates of 5\% for severe anomalies and 3\% for pregnancy loss in exposed pregnancies. ${ }^{6}$ Our results are concordant with the recent Zika-DFA study performed in a similar population, in which neurological defects and fetal losses were reported in $7 \%$ and $1 \%$ of 555 exposed fetuses, respectively (compared with $9 \%$ and $4 \%$ in our study). ${ }^{24}$ Our study also considered clinical and biological aspects up to the first week of life, which may have increased the rate of severe outcomes.

In our study, the most common clinical symptom reported was jaundice, and neonates with a laboratory confirmed Zika virus infection had a moderate elevation of aspartate aminotransferase. Although it was initially believed that Zika virus is not associated with systemic manifestations, mild anaemia, cholestasis, and a moderate elevation of aspartate aminotransferase have been previously described in infected fetuses. ${ }^{26}$ Furthermore, a transient hepatitis, with spontaneous resolution at 4 months of age, has been described in a peripartum infected newborn in French Polynesia. ${ }^{27}$ This suggests that transient liver damage might be part of a moderate CZS, similarly to what is known for congenital cytomegalovirus. ${ }^{17}$ We observed more frequent neurological impairment (hypotonia, hypertonia, and swallowing dysfunction) among fetuses/newborns with a laboratory confirmed congenital Zika virus infection than in those that tested negative. Brainstem dysfunction, manifested by absence of sucking and swallowing, have also been described by others, ${ }^{28}$ even in newborns without microcephaly or severe cerebral radiological anomalies. $^{29}$ Thus, newborns from mothers exposed to Zika virus during their pregnancy should be systematically screened for dysphagia and other subtle neurological impairments, even in the absence of neuroimaging findings.

\section{Strengths and limitations of study}

Our study has several limitations. First of all, information about the sensitivity and specificity of neonatal testing is limited. ${ }^{1}$ In particular, several intrauterine growth restriction; severe anom were not described. ${ }^{25}$ The broader number of patients

\begin{tabular}{|c|c|c|}
\hline Outcomes & Laboratory confirmed cZIKV infection $(n=76)$ & Negative fetal/neonatal ZIKV testing $(n=215)$ \\
\hline Asymptomatic & $34(45,34$ to 56$)$ & $188(87,82$ to 91$)$ \\
\hline Any adverse outcomes & $42(55,44$ to 66$)$ & $27(13,9$ to 18$)$ \\
\hline Mild/moderate signs & $15(20,12$ to 30$)$ & $16(7,5$ to 12$)$ \\
\hline Severe adverse outcomes & $27(36,26$ to 47$)$ & $11(5,3$ to 9$)$ \\
\hline Severe complications & $16(21,13$ to 33$)$ & $10(5,3$ to 8$)$ \\
\hline Fetal loss & $11(14,8.3$ to 24$)$ & $1(0.5,0.1$ to 3$)$ \\
\hline \multicolumn{3}{|c|}{$\begin{array}{l}\text { Outcomes and results of fetal/neonatal testing were available for } 291 \text { fetuses/newborns. Prenatal and postnatal imaging, postnatal examination, and } \\
\text { sample collection were realised in the Centre Hospitalier de l'Ouest Guyanais (prenatal diagnosis, maternity and paediatric units). real-time polymerase } \\
\text { chain reactions and serologies were performed in the national reference centre of arboviruses, Pasteur Cayenne. Each case was reviewed and classified } \\
\text { by three independent reviewers blinded to Zika virus status (Materno-fetal and Obstetrics Research Unit, Centre Hospitalier Universitaire Vaudois). } \\
\text { Discordant classifications were discussed between the three reviewers. } \\
\text { cZIKV=congenital Zika virus. }\end{array}$} \\
\hline
\end{tabular}




\begin{tabular}{|c|c|c|c|c|}
\hline \multirow[b]{2}{*}{ Details of clinical outcomes } & \multicolumn{2}{|c|}{ Laboratory confirmed cZIKV infection ( $n=76)$} & \multicolumn{2}{|c|}{ Negative fetal/neonatal ZIKV testing $(n=215)$} \\
\hline & No (\%) or median (IQR) & $95 \% \mathrm{Cl}$ & No (\%) or median (IQR) & $95 \% \mathrm{Cl}$ \\
\hline Median (IQR) gestational age at delivery, weeks & $38.1(35.3-39.4)$ & 37.6 to 39.0 & $38.4(37.6-39.3)$ & 38.2 to 38.6 \\
\hline Gestational age $<37$ weeks at delivery ${ }^{\star}$ & $8 / 62(13)$ & 6.7 to 23.4 & $24(11)$ & 7.6 to 16.1 \\
\hline \multicolumn{5}{|l|}{ Biometry } \\
\hline Median (IQR) birth weight*, g & $2970(2630-3330)$ & 2865 to 3120 & $3035(2780-3432)$ & 3010 to 3129 \\
\hline Birth weight $<\mathrm{P} 3^{*}$ & $1 / 59(2)$ & 0.3 to 9.0 & $5 / 196(3)$ & 1.1 to 5.8 \\
\hline Birth weight $<\mathrm{P} 10^{\star}$ & $7 / 59(12)$ & 5.9 to 22.5 & 19/196 (10) & 6.3 to 14.6 \\
\hline Head circumference $<2 \mathrm{SD}^{\star}$ & $8 / 61(13)$ & 6.8 to 23.8 & 19/212(9) & 5.8 to 13.6 \\
\hline Head circumference $<3 \mathrm{SD}^{\star}$ & $2 / 61(3)$ & 0.9 to 11.2 & $2 / 212(1)$ & 0.3 to 3.4 \\
\hline \multicolumn{5}{|l|}{ Clinical examination } \\
\hline Jaundice & $19(25)$ & 16.6 to 35.8 & $20(9)$ & 6.1 to 13.9 \\
\hline Hepatomegaly & $5(7)$ & 2.8 to 14.5 & $5(2)$ & 1.0 to 5.3 \\
\hline Hypotonia & $10(13)$ & 7.3 to 22.5 & $11(5)$ & 2.9 to 8.9 \\
\hline Hypertonia & $5(7)$ & 2.8 to 14.5 & $3(1)$ & 0.4 to 4.0 \\
\hline Swallowing dysfunction & $4(5)$ & 2.1 to 12.8 & $1(0.5)$ & 0.1 to 2.6 \\
\hline \multicolumn{5}{|l|}{ Biological parameters-No/No tested (\%) } \\
\hline C reactive protein $>10 \mathrm{mg} / \mathrm{L}$ & 6/53 (11) & 5.3 to 22.6 & 13/191 (7) & 4.0 to 11.3 \\
\hline Haemoglobin $<140 \mathrm{~g} / \mathrm{L}$ & $17 / 57(30)$ & 19.5 to 42.7 & 8/192 (4) & 2.1 to 8.0 \\
\hline Thrombocytes $<150 \mathrm{~g} / \mathrm{L}$ & $7 / 57(12)$ & 6.1 to 23.2 & 9/194 (5) & 2.5 to 8.6 \\
\hline Thrombocytes < $100 \mathrm{~g} / \mathrm{L}$ & $0 / 57(0)$ & 0.0 to 6.3 & 4/194 (2) & 0.8 to 5.2 \\
\hline Median (IQR) total bilirubin, $\mathrm{mmol} / \mathrm{L}$ & $180(134-230)$ & 162 to 209 & $172(145-184)$ & 165 to 178 \\
\hline Severe hyperbilirubinaemiat & 4/47 (9) & 3.3 to 19.9 & $9 / 161(6)$ & 3.0 to 10.3 \\
\hline Aspartate aminotransferase $>50 \mathrm{U} / \mathrm{L}$ & $32 / 52(62)$ & 48.0 to 73.5 & 40/155(26) & 19.6 to 33.2 \\
\hline Aspartate aminotransferase $>100 \mathrm{U} / \mathrm{L}$ & $6 / 52(12)$ & 5.4 to 23.0 & $8 / 155(5)$ & 2.6 to 9.8 \\
\hline Alanine aminotransferase $>50 \mathrm{U} / \mathrm{L}$ & $1 / 52(2)$ & 0.3 to 10.1 & $2 / 155$ (1) & 0.3 to 4.6 \\
\hline
\end{tabular}

studies have shown the progressive disappearance of Zika virus RNA in the maternal-fetal compartments (fetal and maternal blood, amniotic fluid, and neonatal blood and urine). ${ }^{26}{ }^{30}$ In contrast to cytomegalovirus, which may be detected for several months in the urine of congenitally infected newborns, Zika virus RNA was rarely detected in urine samples $(7 / 76 ; 9 \%)$. Although the sensitivity of amniocentesis seems to be limited in cases of congenital Zika virus infection, ${ }^{26}$ it may help to diagnose early fetal infections but was only performed in 12 cases when prenatal ultrasound scans were suggestive of congenital infection. In that context, we cannot exclude false negative results. Of note, severe complications compatible with CZS were observed in $10(5 \%)$ newborns without laboratory evidence of Zika virus infection; either we were not able to detect Zika virus in these cases or other aetiologies may have induced similar complications (the rate of brain anomalies in the general population is estimated to be $3 \%) .{ }^{31}$ The high number of fetuses/neonates with negative results that underwent multiple Zika virus neonatal tests $(80 \%(171 / 215)$ had at least three different samples tested) ensures a low probability of false negative results.

Furthermore, we considered placental and umbilical cord samples in the diagnosis of congenital Zika virus infection, which may be questionable owing to the risk of maternal contamination of these samples. ${ }^{15}$ Nevertheless, the risk of false positive results due to maternal contamination seems to be low in this study. Zika virus status based on umbilical cord blood samples was confirmed at day three of life in all but four neonates. Additionally, we previously detected Zika virus RNA and specific IgM in placental and fetal umbilical cord samples in seven of eight cases with a laboratory confirmed congenital Zika virus infection, even when maternal blood and urine were negative. $^{26}$ When we excluded placental samples from our analysis, maternal-fetal transmission was documented in 18\% (52/282) cases, of which 33\% (17/52) had severe complications at birth. Association between a laboratory confirmation of congenital Zika virus infection and outcomes did not change in our sensitivity analysis.

Secondly, our study focuses on immediate neonatal outcomes. In congenital cytomegalovirus, as many as $13.5 \%$ of newborns who present with no signs/ complications at birth will subsequently develop permanent sequelae, such as motor, cognitive, or vision impairment and sensorineural hearing loss. ${ }^{32}$ Study of developmental milestones and visual and auditory capacity in exposed fetuses will be important. These might be difficult to monitor owing to the lack of follow-up, particularly in newborns with no symptoms. Furthermore, our postnatal radiological analysis was based on transfontanellar ultrasound scans, for which the sensitivity for central nervous system anomalies is lower than for magnetic resonanceimaging or computed tomography scanning for calcifications and skull anomalies. The closest magnetic resonance imaging scanner was located $300 \mathrm{~km}$ away and was therefore not available for this study. Similarly, computed tomography scanning was not routinely available owing to the limited resources of our radiological unit. 
When performed, it was often done after the first week of life and therefore not included here. We cannot exclude the possibility that some mild anomalies were not identified. In this study, nine newborns with severe complications had no anomalies identified on prenatal ultrasound scans. Overall, we recognise that several authors have proposed a broader definition of CZS, ${ }^{33} 34$ based on both advanced techniques (magnetic resonance imaging, computed tomography scanning) and specialised evaluation (ophthalmologist, infectious diseases specialist, and neurologist specialised in paediatrics). Such evaluations are not routinely available in French Guiana, explaining why fundoscopy and results of auditory testing are not described in this paper. We therefore developed a definition of complications compatible with CZS based on specific and non-specific characteristics for congenital Zika virus and TORCH infections observable up to the first week of life, adapted to the local medical capacities of our hospital. This classification might be more applicable in hospitals in low resource settings, often present in tropical regions, at risk of emergence and re-emergence of Zika virus.

Thirdly, conclusions about the impact of the timing of infection on maternal-fetal transmission are difficult to establish as the diagnosis of maternal infection reported here may have occurred much later than the actual maternal infection. Thus, we could not assess the association between trimester of infection and outcomes. The recruitment of infected pregnant women occurred at the time of their first ultrasound scan performed at the prenatal diagnosis unit and was therefore not conducive to evaluation of early fetal consequences of maternal Zika virus infection before 12 weeks' gestation. The rate of early miscarriages, some of them occurring in unrecognised pregnancies or at home without hospital consultation, is thus difficult to determine and was not the focus of our research. Furthermore, as we excluded pregnant patients for whom the diagnosis of Zika virus infection was done at delivery, because of the lack of specific follow-up during pregnancy and early postnatal life, our results cannot provide information on the consequences of late infection in pregnancy.

Finally, our study aimed to describe the burden of congenital Zika virus infection in an epidemic population with a high birth rate and limited access to invasive testing. We cannot exclude the possibility that some of the signs observed were unrelated to congenital Zika virus infection; as illustrated by the population attributable fraction, a confirmed congenital Zika virus infection contributes to only $47 \%$ of adverse outcomes and $61 \%$ of severe adverse outcomes observed here. Some maternal information may have been missed, and invasive testing and complete genetic analyses were not systematically performed (for evident ethical reasons). Nevertheless, potential missing information or additional diagnoses not reported would result in an overestimation of the burden of congenital Zika virus infection observed in this cohort.
Selection bias is expected to be limited, as basic maternal characteristics were similar between patients included in this study and the whole obstetric population delivering at the CHOG in 2016 (see appendix 3). Considering these results when counselling potentially exposed couples living in tropical areas at risk of emergence and re-emergence of Zika virus therefore seems reasonable. ${ }^{35}$

\section{Conclusions}

Our study provides a large comprehensive description of maternal-fetal transmission rates of Zika virus, as well as the burden of congenital infection, during the recent Zika virus epidemic in French Guiana. Despite significant maternal-fetal transmission, the burden of disease seems to be lower than initially suspected and might not differ from those of other well know congenital infections. Although caution is needed, our results suggest that in cases of maternal Zika virus infection, approximately one in four fetuses will become congenitally infected, of which one in three will be affected by severe complications at birth or fetal loss. The population attributable fraction estimates that a confirmed congenital Zika virus infection contributes to $47 \%$ of adverse outcomes and $61 \%$ of severe adverse outcomes observed. This information will help healthcare providers conducting parental counselling.

\section{AUTHOR AFFILIATIONS}

${ }^{1}$ Materno-foetal and Obstetrics Research Unit, Obstetric Service, Department “Femme-Mère-Enfant," University Hospital, Lausanne, Switzerland

${ }^{2}$ Department of Obstetrics and Gynaecology, Centre Hospitalier de l'Ouest Guyanais Franck Joly, Saint-Laurent-du-Maroni, France

${ }^{3}$ Public health department, Centre Hospitalier de l'Ouest Guyanais Franck Joly, Saint-Laurent-du-Maroni, France

${ }^{4}$ Sorbonne Universités, UPMC Univ Paris 06, INSERM, Institut Pierre Louis d'Epidémiologie et de Santé Publique (IPLESP UMRS 1136), Department of Social Epidemiology, Paris, France

${ }^{5}$ Service de gynécologie-obstétrique et médecine de la reproduction, Centre Hospitalier Universitaire de Caen, Universite de Caen Normandie, Caen, Basse-Normandie, France

${ }^{6}$ Laboratory of Virology, National Reference Center for Arboviruses, Institut Pasteur of French Guiana, Cayenne, France

${ }^{7}$ Division of Ultrasound in Obstetrics \& Gynecology, Lis Maternity Hospital, Tel Aviv, Israel

${ }^{8}$ Sourasky Medical Center, Sackler Faculty of Medicine, Tel Aviv University, Tel Aviv, Israel

${ }^{9}$ Service of Clinical Pharmacology, Lausanne University Hospital, Lausanne, Switzerland

${ }^{10}$ School of Pharmaceutical Sciences, University of Geneva and University of Lausanne, Switzerland

${ }^{11}$ Service of Pharmacy, Centre Hospitalier Universitaire Vaudois, Lausanne, Switzerland

We thank all involved personnel at the Centre Hospitalier de l'Ouest Guyannais (CHOG).

Contributors: LP, VL, CP, AJ, GC, MV, and DB conceived and designed the study. $\mathrm{LP}, \mathrm{VL}, \mathrm{CP}, \mathrm{GC}$, and $\mathrm{NH}$ provided care to mothers and prospectively collected the clinical data and samples. LP and CP collected data on neonatal outcomes. GM and GB, as fetal central nervous system experts, contributed to the interpretation of sonograms and the management of congenital Zika virus syndrome cases. DR and SM did all the viral investigations. AP, MV, and DB interpreted the results, did the literature review, and provided critical inputs to the paper. LP, MV, and DB wrote the first version of the report, and all authors critically reviewed and approved the final 
version. The corresponding author attests a similar contribution for LP and MV. The corresponding author attests that all listed authors meet authorship criteria and that no others meeting the criteria have been omitted. LP and DB are the guarantors.

Funding: None.

Competing interests: All authors have completed the ICMJE uniform disclosure form at www.icmje.org/coi disclosure.pdf (available on request from the corresponding author) and declare: no support from any organisation for the submitted work; no financial relationships with any organisations that might have an interest in the submitted work in the previous three years; no other relationships or activities that could appear to have influenced the submitted work.

Ethical approval: The study protocol was approved by the institutional review board of the Centre Hospitalier de l'Ouest Guyannais (CHOG). Patients included in the study provided written informed consent after discussing the objectives of the study.

Data sharing: Technical appendix and statistical code are available from the corresponding author at david.baud@chuv.ch.

Transparency declaration: The corresponding author affirms that this manuscript is an honest, accurate, and transparent account of the study being reported; that no important aspects of the study have been omitted; and that any discrepancies from the study as planned (and, if relevant, registered) have been explained.

This is an Open Access article distributed in accordance with the Creative Commons Attribution Non Commercial (CC BY-NC 4.0) license, which permits others to distribute, remix, adapt, build upon this work non-commercially, and license their derivative works on different terms, provided the original work is properly cited and the use is noncommercial. See: http://creativecommons.org/licenses/by-nc/4.0/.

1 Baud D, Gubler DJ, Schaub B, Lanteri MC, Musso D. An update on Zika virus infection. Lancet2017;390:2099-109. doi:10.1016/S01406736(17)31450-2

2 Rasmussen SA, Jamieson DJ, Honein MA, Petersen LR. Zika Virus and Birth Defects--Reviewing the Evidence for Causality. N Engl / Med2016;374:1981-7. doi:10.1056/ NEJMsr1604338

3 Musso D, Bossin H, Mallet HP, et al. Zika virus in French Polynesia 2013-14: anatomy of a completed outbreak. Lancet Infect Dis2018;18:e172-82. doi:10.1016/S14733099(17)30446-2

4 Vouga M, Musso D, Van Mieghem T, Baud D. CDC guidelines for pregnant women during the Zika virus outbreak. Lancet2016;387:843-4. doi:10.1016/S0140-6736(16)00383-4

5 Brasil P, Pereira JPJr, Moreira ME, et al. Zika Virus Infection in Pregnant Women in Rio de Janeiro. N Engl / Med2016;375:2321-34. doi:10.1056/NEIMoa1602412

6 Shapiro-Mendoza CK, Rice ME, Galang RR, et al, Zika Pregnancy and Infant Registries Working Group. Pregnancy Outcomes After Materna Zika Virus Infection During Pregnancy - U.S. Territories, January 1 2016-April 25, 2017. MMWR Morb Mortal Wkly Rep2017;66:61521. doi:10.15585/mmwr.mm6623e1

7 Charrier R. Synthèse démographique de la Guyane - Une démographie toujours dynamique. 2017. https://www.insee.fr/fr/ statistiques/2559184\#titre-bloc-3.

8 Agence régionale de santé. Surveillance du virus Zika aux Antilles Guyane. Point épidémiologique du 06 octobre 2016. 2016. http://invs.santepubliquefrance.fr/Publications-et-outils/Pointsepidemiologiques/Tous-les-numeros/Antilles-Guyane/2016/ Situation-epidemiologique-du-virus-Zika-aux-Antilles-Guyane.-Pointau-6-octobre-2016.

9 Agence régionale de santé. Emergence du virus Zika aux Antilles Guyane. Point épidémiologique du 21 juillet 2016. 2016. http:// invs.santepubliquefrance.fr/fr/Publications-et-outils/Pointsepidemiologiques/Tous-les-numeros/Antilles-Guyane/2016/ Situation-epidemiologique-du-virus-Zika-aux-Antilles-Guyane.-Pointau-21-juillet-2016.

10 Flamand C, Fritzell C, Matheus S, et al. The proportion of asymptomatic infections and spectrum of disease among pregnant women infected by Zika virus: systematic monitoring in French Guiana, 2016. Euro Surveill2017;22. doi:10.2807/1560-7917. ES.2017.22.44.17-00102

11 Pomar L, Malinger G, Benoist G, et al. Association between Zika virus and fetopathy: a prospective cohort study in French Guiana. Ultrasound Obstet Gynecol2017;49:729-36. doi:10.1002/ uog. 17404

12 Pomar L, Rousset D, Jolivet A, Pomar C, Lambert V. Reply. Ultrasound Obstet Gynecol2017;49:810. doi:10.1002/uog.17510
13 Papageorghiou AT, Thilaganathan B, Bilardo CM, et al. ISUOG Interim Guidance on ultrasound for Zika virus infection in pregnancy: information for healthcare professionals. Ultrasound Obstet Gynecol2016;47:530-2. doi:10.1002/uog.15896

14 Oladapo OT, Souza JP, De Mucio B, de León RG, Perea W, Gülmezoglu AM, WHO Guideline Development Group. WHO interim guidance on pregnancy management in the context of Zika virus infection. Lancet Glob Health2016;4:e510-1. 10.1016/S2214-109X(16)30098-5

15 Adebanjo T, Godfred-Cato S, Viens L, et al, Contributors. Update: Interim Guidance for the Diagnosis, Evaluation, and Management of Infants with Possible Congenital Zika Virus Infection - United States, October 2017. MMWR Morb Mortal Wkly Rep2017;66:1089-99. 10.15585/mmwr.mm6641a1

16 Leruez-Ville M, Stirnemann J, Sellier Y, et al. Feasibility of predicting the outcome of fetal infection with cytomegalovirus at the time of prenatal diagnosis. Am J Obstet Gynecol2016;215:342.e1-9. 10.1016/j.ajog.2016.03.052

17 Leruez-Ville M, Ville Y. Fetal cytomegalovirus infection. Best Pract Res Clin Obstet Gynaecol2017;38:97-107. 10.1016/j. bpobgyn.2016.10.005

18 Lambert V, Pomar L, Malinger G.The Zika virus epidemic in French Guiana: proposition of an ultrasound based score for the diagnosis of fetal congenital Zika virus syndrome. Ultrasound Obstet Gynecol2017;50(Suppl 1):19.

19 Vouga M, Baud D. Imaging of congenital Zika virus infection: the route to identification of prognostic factors. Prenat Diagn2016;36:799-811. 10.1002/pd.4880

20 Giakoumelou S, Wheelhouse N, Cuschieri K, Entrican G, Howie SEM, Horne AW. The role of infection in miscarriage. Hum Reprod Update2016;22:116-33. 10.1093/humupd/dmv041

21 Smith GCS. Screening and prevention of stillbirth. Best Pract Res Clin Obstet Gynaecol2017;38:71-82. 10.1016/j.bpobgyn.2016.08.002

22 Dollard SC, Grosse SD, Ross DS. New estimates of the prevalence of neurological and sensory sequelae and mortality associated with congenital cytomegalovirus infection. Rev Med Virol2007:17:355-63.10.1002/rmv.544

23 Lipitz S, Yinon Y, Malinger G, et al. Risk of cytomegalovirus-associated sequelae in relation to time of infection and findings on prenatal imaging. Ultrasound Obstet Gynecol2013;41:508-14. 10.1002/ uog.12377

24 Hoen B, Schaub B, Funk AL, et al. Pregnancy Outcomes after ZIKV Infection in French Territories in the Americas. N EnglJ Med2018.378.985-94.10.1056/NEIMoa1709481

25 Nogueira ML, Nery Júnior NRR, Estofolete CF, et al. Adverse birth outcomes associated with Zika virus exposure during pregnancy in São José do Rio Preto, Brazil. Clin Microbiol Infect2018;24:646-52. 10.1016/j.cmi.2017.11.004

26 Schaub B, Vouga M, Najioullah F, et al. Analysis of blood from Zika virus-infected fetuses: a prospective case series. Lancet Infect Dis2017:17:520-7. 10.1016/S1473-3099(17)30102-0

27 Besnard M, Dub T, Gérardin P. Outcomes for 2 Children after Peripartum Acquisition of Zika Virus Infection, French Polynesia, 2013-2014. Emerg Infect Dis2017;23:1421-3. 10.3201/ eid2308.170198

28 Leal MC, van der Linden V, Bezerra TP, et al. Characteristics of Dysphagia in Infants with Microcephaly Caused by Congenital Zika Virus Infection, Brazil, 2015. Emerg Infect Dis 2017;23:1253-9. 10.3201/eid2308.170354

29 Besnard M, Eyrolle-Guignot D, Guillemette-Artur P, et al. Congenital cerebral malformations and dysfunction in fetuses and newborns following the 2013 to 2014 Zika virus epidemic in French Polynesia. Euro Surveill2016;21. 10.2807/1560-7917.ES.2016.21.13.3018

30 Rodó C, Suy A, Sulleiro E, et al. In utero negativization of Zika virus in a foetus with serious central nervous system abnormalities. Clin Microbiol Infect2018;24:549.e1-3. 10.1016/j.cmi.2017.09.022

31 Oliveira CIF, Fett-Conte AC. Birth defects: Risk factors and consequences. J Pediatr Genet2013;2:85-90.

32 Manicklal S, Emery VC, Lazzarotto T, Boppana SB, Gupta RK. The "silent" global burden of congenital cytomegalovirus. Clin Microbiol Rev2013:26:86-102. 10.1128/CMR.00062-12

33 Del Campo M, Feitosa IML, Ribeiro EM, et al, Zika Embryopathy Task Force-Brazilian Society of Medical Genetics ZETF-SBGM. The phenotypic spectrum of congenital Zika syndrome. Am J Med Genet A2017;173:841-57. 10.1002/ajmg.a.38170

34 Moore CA, Staples JE, Dobyns WB, et al.Characterizing the Pattern of Anomalies in Congenital Zika Syndrome for Pediatric Healthcare Providers. JAMA Pediatr2017;171:288-95. 10.1001/ jamapediatrics.2016.3982

35 Musso D, Cao-Lormeau VM. Is the Zika threat over? Clin Microbiol Infect2018;24:566-7. 10.1016/j.cmi.2018.03.007

\section{Appendix 1-4}

